\title{
Quilombos e a Luta contra o Racismo no Contexto da Pandemia'
}

Givânia Maria da Silva²

Bárbara Oliveira Souza ${ }^{3}$

1 INTRODUÇÃO

Este artigo tem como objeto refletir sobre a situação vivenciada no contexto atual de pandemia ${ }^{4}$ causada pelo novo coronavírus nas comunidades quilombolas do Brasil. Com impactos globais bastante significativos, os efeitos da pandemia têm causado danos mais acentuados em determinados grupos populacionais no Brasil? O racismo estrutural de nossa sociedade tem aprofundado sua marca de desigualdade nessa situaçáo de pandemia? Como os quilombos estáo vivenciando essa realidade? Essas são questóes que buscaremos abordar neste artigo, em diálogo com as manifestaçóes e estratégias dos quilombolas, por meios de suas organizaçóes, para enfrentar o racismo estrutural no Brasil, no contexto da pandemia da Covid-19.

\section{TERRITÓRIOS QUILOMBOLAS E RACISMO ESTRUTURAL}

As comunidades quilombolas têm vivenciado historicamente efeitos do racismo estrutural (Almeida, 2018). Diversas barreiras no acesso a políticas públicas fundamentais, como as de saúde, educação e as voltadas à regularização fundiária de seus territórios tradicionais, são presentes há geraçóes nas comunidades. O significativo grau de vulnerabilidade nos quilombos se aprofunda em situaçôes de crises graves, como a atual. A limitada garantia dos territórios quilombolas é um dos elementos que deve ser destacado.

No contexto atual de crise da saúde pública, a maior parte das comunidades náo tem assegurado o direito a seus territórios, onde apenas 246 títulos foram expedidos para 357 comunidades quilombolas, ${ }^{5}$ em um universo de mais de 6 mil comunidades no país. Os quilombos convivem ainda, em diversas situaçôes, com conflitos, ameaças de expropriação e violências (CONAQ e Terra de Direitos, 2018). Esses são fatores necessários para avaliarmos o contexto atual no qual as comunidades quilombolas estão imersas na luta contra os efeitos da Covid-19.

As ameaças de remoçáo de seus territórios tradicionais são outro fator que tem agravado a fragilidade de algumas comunidades quilombolas no país. Neste cenário de pandemia, comunidades quilombolas, como as situadas no território quilombola de Alcântara, no Maranhão, vivenciam

1. DOI: http://dx.doi.org/10.38116/bapi26art9

2. Professora substituta da Universidade de Brasília (UnB); pesquisadora associada da Associação de Pesquisadores Negros e Negras (ABPN), do Núcleo de Estudos Afro-Brasileiros (Neab/ Centro de Estudos Avançados Multidisciplinares - Ceam/UnB/Brasil) e Grupo de Estudos em Políticas Públicas, História e Educação das Relações Raciais e de Gênero (Geppherg/UnB); pesquisadora do grupo de pesquisa Cauim/UnB; cofundadora da Coordenação Nacional das Comunidades Negras Rurais Quilombolas (CONAQ); mestre em políticas públicas e gestão da educação (2012) pela UnB; e doutoranda em sociologia pela UnB.

3. Professora voluntária da UnB vinculada ao Neab/Ceam/UnB, onde ministra disciplinas sobre a questão racial, povos e comunidades tradicionais e sustentabilidade; pesquisadora associada ao Neab/UnB e ao Laboratório de Antropologias da T/Terra (T/terra/UnB); e doutora em antropologia pela UnB.

4. Declarada pela Organização Mundial da Saúde (OMS) desde 11 de março de 2020.

5. Dados de maio de 2020, fornecidos pelo Instituto Nacional de Colonização e Reforma Agrária (Incra), reunindo títulos de diversos órgãos, como Instituto de Terras do Pará (Iterpa), Instituto de Colonização e Terras do Maranhão (Iterma) e o próprio Incra. 
tensões, com ameaças de novos deslocamentos e remoçóes de parte das comunidades, em razão da tentativa de expansão da base espacial ali situada. Uma série de açóes que violam o direito de consulta prévia, livre e assistida, e que não asseguram o direito à terra previsto na Constituição Federal de 1988, no art. 68 do Ato das Disposiçóes Constitucionais Transitórias (ADCT), têm sido tomadas no território de Alcântara, em pleno contexto de pandemia. ${ }^{6}$

A existência das comunidades é fundamentalmente vinculada à garantia dos seus territórios. Os quilombos mantêm vínculos profundos de sua identidade com a terra/território tradicional, a partir dos modos de vida e dos processos de resistência à opressão histórica sofrida, sejam no meio rural ou urbano. A ruralidade é majoritariamente presente, contudo não é uma condição exclusiva das comunidades quilombolas.

Terra e território possuem outros sentidos e usos. Envolvem plantio, produção, vivências e expressões das manifestaçôes culturais, celebrações, construçôes de espaços sagrados e de vínculo com as memórias ancestrais. As relaçóes e os modos de vida associam-se a outras características de natureza cultural e simbólica, e a aspectos político-organizativos, como as lutas por reconhecimento e direitos (Souza, 2016; Silva, 2012).

No Brasil, a batalha das comunidades quilombolas por seus territórios se fundamenta em marcos legais, como o art. 68 do ADCT $^{7}$ e os arts. $215^{8}$ e $216^{9}$ da Constituição Federal de 1988. É dever do Estado brasileiro garantir os territórios dos quilombos, assim como proteger seus os modos de viver, fazer e criar bens materiais e imateriais associados à identidade e à memória dos diferentes grupos formadores da sociedade (art. 268 do ADCT, arts. 15 e 216 da Constituição Federal de 1988).

Contudo, cabe destacar a omissão do Estado em atuar no enfrentamento dos efeitos da pandemia da Covid-19 nos quilombos. A atual situação tem deixado os quilombolas ainda mais fragilizados, como destaca Selma Dealdina, quilombola do quilombo Angelim III, no Espírito Santo.

Nosso povo não está conseguindo fazer os testes. Não está tendo testes. Vão aos postos de saúde e lá pedem para voltar, porque não tem. Na cesta básica é muita conversa e pouca ação. É muito decreto, portaria, mas as cestas não estão chegando ao nosso povo, que está com fome. Não está chegando a quem de fato precisa, por causa de impedimento, não tem telefone, não tem luz. Falando do auxílio emergencial, quem tem fome, quem precisa, não será atendido porque a forma

6. Informação disponível em: <https://noticias.uol.com.br/colunas/rubens-valente/2020/03/28/governo-bolsonaro-alcantara-quilombolas. htm>. Acesso em: 27 ago. 2020.

7. "Aos remanescentes das comunidades dos quilombos que estejam ocupando suas terras é reconhecida a propriedade definitiva, devendo o Estado emitir-Ihes os títulos respectivos" (Brasil, 2016, p. 160).

8. Trecho incluído pela Emenda Constitucional no 48, de 2005: "O Estado garantirá a todos o pleno exercício dos direitos culturais e acesso às fontes da cultura nacional, e apoiará e incentivará a valorização e a difusão das manifestações culturais. § 1 0 Estado protegerá as manifestações das culturas populares, indígenas e afro-brasileiras, e das de outros grupos participantes do processo civilizatório nacional. § 2ํㅡ lei disporá sobre a fixação de datas comemorativas de alta significação para os diferentes segmentos étnicos nacionais. § 3ำ A lei estabelecerá o Plano Nacional de Cultura, de duração plurianual, visando ao desenvolvimento cultural do país e à integração das ações do poder público (...)" (Brasil, 2016, p. 126).

9. "Constituem patrimônio cultural brasileiro os bens de natureza material e imaterial, tomados individualmente ou em conjunto, portadores de referência à identidade, à ação, à memória dos diferentes grupos formadores da sociedade brasileira, nos quais se incluem: I - as formas de expressão; II - os modos de criar, fazer e viver; III - as criações científicas, artísticas e tecnológicas; IV - as obras, objetos, documentos, edificações e demais espaços destinados às manifestações artístico-culturais; $V$ - os conjuntos urbanos e sítios de valor histórico, paisagístico, artístico, arqueológico, paleontológico, ecológico e científico. § 10 0 poder público, com a colaboração da comunidade, promoverá e protegerá 0 patrimônio cultural brasileiro, por meio de inventários, registros, vigilância, tombamento e desapropriação, e de outras formas de acautelamento e preservação" (Brasil, 2016, p. 126). 
como foi usada para inscrição, pela internet, por telefone, não funciona nos quilombos. Os anseios e dúvidas continuam. ${ }^{10}$

Descreveremos, a seguir, alguns aspectos que apontam a histórica desigualdade no acesso a políticas públicas e em como esses elementos impactam segmentos vulneráveis, como as comunidades quilombolas no Brasil.

\section{DIVERSIDADE E DESIGUALDADE BRASILEIRA EM TEMPOS DE PANDEMIA}

A emergência na saúde pública tem apresentado resultados bastante preocupantes em todo o mundo. No Brasil, a situação é grave, pois o país está em segundo lugar no número de mortos, em escala global, assim como no quantitativo de casos. São mais de 146 mil pessoas que faleceram em decorrência da Covid-19, e um quantitativo de indivíduos superior a 4,9 milhóes foi infectado. ${ }^{11}$

A forma como ocorre a incidência da pandemia sobre as pessoas no Brasil, contudo, também reflete a desigualdade estrutural existente. Segundo o Ministério da Saúde, em dados publicados em seus boletins epidemiológicos, tem havido o crescimento percentual de pretos e pardos entre internados e entre mortos pela Covid-19. ${ }^{12}$ Há registros preocupantes do crescimento da doença em quilombos, somando mais de 165 mortes e mais de 4.590 infectados. ${ }^{13}$ Esse crescimento se reflete, também, em terras indígenas, evidenciando o racismo estrutural que opera em desfavor de negros e indígenas.

O Brasil é composto por uma população muito diversa. Segundo a Pesquisa Nacional por Amostra de Domicílios (PNAD) Contínua de 2019, realizada pelo Instituto Brasileiro de Geografia e Estatística (IBGE), pretos e pardos são a maioria no Brasil. Os dados mostram que a população que se declara preta representa 9,4\%, e parda, 46,8\%. Juntos, equivalem a 56,2\% da população, enquanto os brancos são 42,7\% (IBGE, 2019). Ainda de acordo com o IBGE, existem 305 etnias indígenas $^{14}$ e mais de 800 mil ciganos. ${ }^{15}$

As comunidades quilombolas, por sua vez, estão presentes em todas as regióes do Brasil, de norte a sul, de leste a oeste, mantendo a luta histórica pela garantia dos seus direitos. Na atualidade são mais de 6 mil comunidades em todo o país (CONAQ e Terra de Direitos, 2018). Dessas, 3.432 comunidades quilombolas são certificadas pela Fundação Cultural Palmares, ${ }^{16}$ das quais pouco mais de trezentas têm seus territórios titulados. Segundo o IBGE, há presença quilombola em 1.672 dos 5.570 municípios brasileiros, ou seja, em cerca de 30,1\% dos municípios brasileiros tem quilombos. Ainda de acordo com o IBGE, existem 5.972 localidades quilombolas no país. ${ }^{17}$

Essa rica diversidade étnico-racial, entretanto, está ancorada em uma estrutural desigualdade. O Brasil é atualmente um dos países mais desiguais do mundo, com o índice de Gini de 0,509

10. Disponível em: <https://noticias.uol.com.br/colunas/rubens-valente/2020/04/25/coronavirus-quilombolas-brasil.htm>. Acesso em: 2 out. 2020. 11. Disponível em: <https://covid.saude.gov.br>. Acesso em: 5 out. 2020.

12. Disponível em: <https://g1.globo.com/bemestar/coronavirus/noticia/2020/05/18/em-4-semanas-mortes-de-pretos-e-pardos-por-covid-19passam-de-328percent-para-548percent.ghtml>.

13. Disponível em: <https://www.quilombosemcovid19.org/>. Acesso em: 5 out. 2020.

14. Disponível em: <indigenas.ibge.gov.br>. Acesso em: 20 set. 2019.

15. Disponível em: <http://basilio.fundaj.gov.br/pesquisaescolar/index.php?option=com_content\&id=914\%3Aciganos-no-brasil>.

16. Certidões expedidas pela Fundação Cultural Palmares às comunidades remanescentes de quilombos. Essa base foi atualizada pela Portaria no 36/2020, publicada no Diário Oficial da União em 21/2/2020. Disponível em: <http://www.palmares.gov.br/?page_id=37551>. Acesso em: 2 jun. 2020.

17. Disponível em: <https://quilombolas-ibgedgc.hub.arcgis.com/>. Acesso em: 27 ago. 2020. 
(IBGE, 2019). A desigualdade racial e de gênero está presente no mercado de trabalho, no acesso à educação, à saúde. Os quilombos são parte dos grupos afetados por essa desigualdade.

Os estudos apontam que as desigualdades, já fortemente presentes entre os negros, mulheres, povos indígenas, quilombolas e outras comunidades tradicionais, devem se agravar com a pandemia causada pela Covid-19. As maiores vítimas da pandemia são os segmentos mais vulneráveis de nossa sociedade.

A principal organização dos quilombolas do país, a Coordenação Nacional de Comunidades Negras Rurais Quilombolas (CONAQ), tem destacado os fatores estruturais sobre as consequências do alastramento da pandemia nos territórios quilombolas. Além disso, tem denunciado tal situação ao poder público e formulado proposiçóes com o objetivo de reduzir os danos nas comunidades. Porém, poucas respostas têm sido dadas pelas autoridades. Ao contrário; açóes como os vetos do Executivo aos projetos de lei (PLs) nos $1142 / 2020^{18}$ e 735/2020 ${ }^{19}$ demonstram as dificuldades e o racismo que os quilombolas, indígenas, agricultores familiares e demais povos e comunidades tradicionais vêm enfrentado no contexto da pandemia de Covid-19.

As ações de prevenção recomendadas pelas autoridades de saúde, no contexto da pandemia do novo coronavírus, são precárias em muitas comunidades quilombolas, por desigualdades históricas, como as más condiçóes de acesso à água em parte significativa dos territórios, onde apenas 15\% dos domicílios têm acesso à rede pública de água (Pinto et al., 2014), a fragilidade nas políticas de saúde em quilombos e o maior risco de incidência de situaçóes de insegurança alimentar em quilombos. ${ }^{20}$ Os dados de saneamento quilombola indicam fatores também preocupantes nesse contexto de pandemia, em que mais de $70 \%$ das comunidades quilombolas têm condiçóes precárias de saneamento, como valas a céu aberto e fossas rudimentares. ${ }^{21}$ Pesquisas indicam, ainda, que $75 \%$ da população quilombola vive em situação de extrema pobreza (op. cit.). Esses aspectos têm sido denunciados historicamente pelo movimento quilombola. Durante a pandemia, essa narrativa ganhou força exatamente pelo risco de piora na desigualdade já existente. ${ }^{22}$

A crítica situação das políticas públicas para as comunidades quilombolas e para a população negra tem outros pontos que demandam atenção. Em estudo realizado pelo Instituto de Estudos Socioeconômicos (Inesc), há um detalhamento de como nos últimos anos têm se agravado a situação das políticas de igualdade racial (Zigoni, 2020). De 2014 a 2019 houve um corte de $80 \%$ dos recursos destinados às políticas de igualdade racial. Em 2020, a situação se complexificou com a extinção do Programa 2034, intitulado Promoção da Igualdade Racial e Superação do Racismo, existente no Plano Plurianual (PPA) 2016-2019, mas não incorporado ao PPA 2020-2023.

Zigoni (2020) destaca ainda o corte descomunal de orçamento para políticas para comunidades quilombolas. De 2017 em diante não houve nenhum recurso para regularização fundiária de territórios quilombolas, da Ação $210 \mathrm{~V}$ do PPA (Promoção e Fortalecimento da Estruturação Produtiva

18. Disponível em: <https://congressoemfoco.uol.com.br/direitos-humanos/mais-de-200-entidades-pedem-derrubada-de-vetos-a-protecaoindigena-e-quilombola/>. Acesso em: 27 ago. 2020.

19. Disponível em: <https://conexaoto.com.br/2020/08/25/senadores-criticam-veto-de-bolsonaro-ao-auxilio-para-agricultores-familiares> . Acesso em: 27 ago. 2020.

20. Aspectos indicados em Brasil (2008).

21. Considerou-se na análise apenas os quilombos que responderam sobre saneamento. Dados disponíveis em: <http://www.metaestrategica. com.br/seppir2.0/dashboard.html\#/layout/pbq/eixo2 >. Acesso em: 5 out. 2020.

22. Disponivel em: <https://quilombosemcovid19.org/>. Acesso em: 26 ago. 2020. 
da Agricultura Familiar, Pequenos e Médios Produtores Rurais). Em 2020, dos R \$ 3,2 milhóes previstos para essa ação, nada foi executado até agosto. A Fundação Cultural Palmares, por sua vez, também não executou nenhum recurso para comunidades quilombolas em 2020, tampouco o Ministério da Mulher, da Família e dos Direitos Humanos.

As políticas públicas existentes para as comunidades quilombolas, que já traziam um histórico de não atenderem muitas das demandas fundamentais das comunidades, estão hoje reduzidas a quase nada. As políticas públicas universais, como as de saúde, também têm sofrido duros golpes nos últimos anos. No contexto grave da pandemia, cabe fazer referência ao subfinanciamento das políticas públicas de saúde federais em $\mathrm{R} \$ 20$ bilhóes. Isso ocorre em decorrência da medida de Teto dos Gastos Públicos, que resulta no congelamento dos recursos da saúde e educaçáo por vinte anos (Zigoni, 2020).

\section{CONSIDERAÇÕES FINAIS}

A discriminação racial e a desigualdade, tão presentes na sociedade brasileira, e que marcam o histórico da relação do Estado brasileiro com os quilombos, estáo em franco processo de agravamento na situação da pandemia. Esses são aspectos que devem ser tratados a partir de medidas a serem tomadas pelos governos locais, estaduais e pelo governo federal, com a devida urgência necessária, obedecendo à Constituição Federal de 1988 e a tratados e convençóes internacionais dos quais o Brasil é signatário.

Cabe ao Estado brasileiro assegurar a sua população, e às comunidades quilombolas, os direitos básicos e a atenção à saúde, de forma a efetivar políticas públicas qualificadas para a redução das desigualdades estruturais que atingem negros, mulheres, indígenas de forma mais determinante, ainda mais agravadas pelos efeitos da pandemia.

O que é possível visualizar, a partir do monitoramento das políticas públicas e das açôes dos governos, nesse contexto crítico de pandemia do novo coronavírus, é que têm sido sistematicamente reduzidas as iniciativas voltadas às comunidades quilombolas e à população negra, e aumentada a violação dos direitos desses cidadãos e cidadâs. A situação de vulnerabilidade, vivenciada secularmente nos quilombos, tem se agravado consideravelmente na atual conjuntura.

A luta pelos direitos fundamentais das comunidades quilombolas, todavia, segue em curso, com a incorporação de estratégias necessárias nesse contexto delicado. A elaboração de um banco de dados de monitoramento dos efeitos da Covid-19 nas comunidades e a articulação junto ao Poder Legislativo são alguns dos exemplos. ${ }^{23}$ Outro fato de mobilização relevante é o ingresso da Arguição de Descumprimento de Preceito Fundamental (ADPF), junto ao Supremo Tribunal Federal (STF), pela CONAQ e alguns partidos políticos, ${ }^{24}$ em funçáo da inexistência de um plano de ação que considere as vulnerabilidades específicas dos quilombos em relaçáo à situação de pandemia. Com a resistência e a inspiração das raízes ancestrais, seguem em curso as estratégias das comunidades frente a esse contexto desigual e racista em que vive a sociedade brasileira.

23. Site de monitoramento disponível em: <https://quilombosemcovid19.org/>. Acesso em: 26 ago. 2020.

24. Disponível em: <https://diplomatique.org.br/supremo-deve-decidir-sobre-protecao-de-comunidades-quilombolas/>. Acesso em: 2 out. 2020. 


\section{REFERÊNCIAS}

ALMEIDA, S. L. de. O que é racismo estrutural? Belo Horizonte: Letramento, 2018.

BRASIL. Ministério do Desenvolvimento Social e Combate à Fome. Políticas sociais e chamada nutricional quilombola: estudos sobre condiçóes de vida nas comunidades e situação nutricional das crianças. Brasília: MDS; Sagi, 2008. (Cadernos de Estudos Desenvolvimento Social em Debate, n. 9). Disponível em: <https://aplicacoes.mds.gov.br/sagirmps/ferramentas/docs/caderno\%20-\%20 09.pdf>.

Constituição da República Federativa do Brasil. Brasília: Senado Federal, 2016.

CONAQ - COORDENAÇÃO NACIONAL DAS COMUNIDADES NEGRAS RURAIS QUILOMBOLAS; TERRA DE DIREITOS. (Org.). Racismo e violência contra quilombos no Brasil. Curitiba: Terra de Direitos, 2018.

PINTO, A. R. et al. (Org.). Quilombos no Brasil: segurança alimentar e nutricional em territórios titulados. Brasília: MDS; Sagi, 2014. (Cadernos de Estudos Desenvolvimento Social em Debate, n. 20). Disponível em: <http://www.mds.gov.br/webarquivos/publicacao/brasil_sem_miseria/ cadernos_de_estudos20.pdf>.

SILVA, G. M. da. Educaçáo como processo de luta política: a experiência de "educação diferenciada" do território quilombola de Conceição das Crioulas. 2012. 199 f. Dissertação (Mestrado) - Universidade de Brasília, Brasília, 2012.

SOUZA, B. O. Aquilombar-se: panorama sobre o Movimento Quilombola Brasileiro. Curitiba: Appris, 2016.

ZIGONI, C. Orçamento público voltado para as comunidades quilombolas no contexto da pandemia Covid-19. Brasília: Inesc, ago. 2020.

\section{BIBLIOGRAFIA COMPLEMENTAR}

BRASIL. Lei no 601, de 18 de setembro de 1850. Dispóe sobre as terras devolutas do Império. Coleção de Leis do Brasil, Rio de Janeiro, 1850. Disponível em: <https://cutt.ly/9jSGesP >.

Lei no 4.504, de 30 de novembro de 1964. Dispóe sobre o Estatuto da Terra, e dá outras providências. Diário Oficial da Uniáo, Brasília, 30 nov. 1964. Disponível em: <http://www.planalto. gov.br/ccivil_03/leis/14504.htm>.

. Decreto no 4.887, de 20 de novembro de 2003. Regulamenta o procedimento para identificação, reconhecimento, delimitação, demarcação e titulação das terras ocupadas por remanescentes das comunidades dos quilombolas de que trata o art. 68 do Ato das Disposiçóes Constitucionais Transitórias. Diário Oficial da União, Brasília, 21 nov. 2003.

GEHLEN, I. (Coord.). Diversidade e proteçáo social: estudos quanti-qualitativos das populaçóes de Porto Alegre. Porto Alegre: Centhury, 2008. 
GOMES, F. dos S. Mocambos e quilombos: uma história do campesinato negro no Brasil. 1. ed. São Paulo: Claro Enigma, 2015. (Coleção Agenda Brasileira).

SOUZA, B. O. Aquilombar-se: panorama histórico, político e identitário sobre o Movimento Quilombola Brasileiro. 2008. Dissertação (Mestrado) - Universidade de Brasília, Brasília, 2008. 
